\title{
Impact of Air Pollution and Trans-Boundary Haze on Nation-Wide Emergency Department Visits and Hospital Admissions in Singapore
}

Sze Ling $\underline{\text { Chan }},{ }^{1}{ }_{P h D},{ }^{*}$ Andrew FW $\underline{\text { Ho }},{ }^{2,3}{ }_{M B B S, M M e d},{ }^{*}$ Huicong Ding, ${ }^{4}{ }_{B E n V S t}$, Nan Liu,,${ }^{1,2}{ }_{P h D}$, Arul Earnest,${ }^{5}{ }_{P h D}$, Mariko S $\underline{\mathrm{Koh}},{ }^{6,7}{ }_{M B B S, ~ M R C P}$, Jolyn ST $\underline{\text { Chuah }},{ }^{8}{ }_{M S c}$, Zheng Yi Lau, ${ }^{9}{ }_{M S c}$, Kelvin Bryan Tan, ${ }^{9,10}{ }_{P h D}$, Huili Zheng, ${ }^{11} M S c$, Geoffrey G Morgan, ${ }^{12}{ }^{2 h D}$, Marcus EH Ong, ${ }^{1,2,3}{ }^{M B B S, M P H}$

\begin{abstract}
Introduction: Air pollution is associated with adverse health outcomes. However, its impact on emergency health services is less well understood. We investigated the impact of air pollution on nation-wide emergency department (ED) visits and hospital admissions to public hospitals in Singapore. Materials and Methods: Anonymised administrative and clinical data of all ED visits to public hospitals in Singapore from January 2010 to December 2015 were retrieved and analysed. Primary and secondary outcomes were defined as ED visits and hospital admissions, respectively. Conditional Poisson regression was used to model the effect of Pollutant Standards Index (PSI) on each outcome. Both outcomes were stratified according to subgroups defined a priori based on age, diagnosis, gender, patient acuity and time of day. Results: There were 5,791,945 ED visits, of which 1,552,187 resulted in hospital admissions. No significant association between PSI and total ED visits (Relative risk [RR], 1.002; 99.2\% confidence interval $[C I], 0.995-1.008 ; P=0.509)$ or hospital admissions (RR, 1.005; 99.2\% CI, 0.996-1.014; $P=0.112$ ) was found. However, for every 30 -unit increase in PSI, significant increases in ED visits (RR, 1.023; 99.2\% CI, 1.011-1.036; $P=1.24 \times$ $\left.10^{-6}\right)$ and hospital admissions (RR, 1.027; 99.2\% CI, 1.010-1.043; $P=2.02 \times 10^{-5}$ ) for respiratory conditions were found. Conclusion: Increased PSI was not associated with increase in total ED visits and hospital admissions, but was associated with increased ED visits and hospital admissions for respiratory conditions in Singapore.
\end{abstract}

Ann Acad Med Singapore 2020;49:78-87

Key words: Epidemiology, Healthcare utilisation, PSI, Public health, Time series

\section{Introduction}

Air pollution is a growing issue in public health throughout the world. There is substantial evidence on the effect air pollution has on cardiovascular and respiratory morbidity and mortality, especially from nitrogen dioxide $\left(\mathrm{NO}_{2}\right)$, ozone $\left(\mathrm{O}_{3}\right)$, particulate matter $(\mathrm{PM})$ and sulphur dioxide $\left(\mathrm{SO}_{2}\right) \cdot{ }^{1-5}$ Globally, air pollution accounts for
$>4$ million premature deaths annually, largely through aggravation of heart diseases, lung cancer, respiratory diseases and stroke. ${ }^{6}$

In Singapore, annual episodes of trans-boundary haze blown in from nearby countries in Southeast Asia pose major health risks as they disrupt the activities of her citizens and stretch her health services. ${ }^{7}$ Haze

\footnotetext{
${ }^{1}$ Health Services Research Centre, Singapore Health Services, Singapore

${ }^{2}$ Health Services and Systems Research, Duke-NUS Medical School, Singapore

${ }^{3}$ Department of Emergency Medicine, Singapore General Hospital, Singapore

${ }^{4}$ Department of Biological Science, Faculty of Science, National University of Singapore, Singapore

${ }^{5}$ Department of Epidemiology and Preventive Medicine, Monash University School of Public Health and Preventive Medicine, Australia

${ }^{6}$ Department of Respiratory and Critical Care Medicine, Singapore General Hospital, Singapore

${ }^{7}$ Duke-NUS Medical School, Singapore

${ }^{8}$ School of Computing, National University of Singapore, Singapore

${ }^{9}$ Policy Research and Evaluation Division, Ministry of Health, Singapore

${ }^{10}$ Saw Swee Hock School of Public Health, National University of Singapore, Singapore

${ }^{11}$ National Registry of Diseases Office, Health Promotion Board, Singapore

${ }^{12}$ Sydney School of Public Health, University of Sydney, Australia

*Joint first authors

Address for Correspondence: Dr Chan Sze Ling, Health Services Research Centre, Singapore Health Services, 20 College Road, Academia, Discovery Tower, Level 6, Singapore 169856.

Email: chan.sze.ling@singhealth.com.sg
} 
from neighbouring countries is traced to smoke from seasonal burning of forests to clear lands for agriculture purposes. ${ }^{8,9}$ The fires produce airborne PM from smoke emission that is transported by trans-boundary winds, leading to large-scale haze episodes that enveloped much of the region. ${ }^{10}$ The frequency of haze episodes in Singapore had increased over the last 10 years, with major episodes occurring in 2009, 2013 and 2015. ${ }^{11-13}$

Numerous studies have examined the impact of air pollution on specific disease risks and health outcomes; however, only a handful of reports have examined the impact on overall demand and utilisation of health services. This investigation is important for 2 reasons. First, it facilitates preparation to meet the sudden surge in demand for health services during episodes of haze. Second, it provides valuable data and information that can help to quantify the economic cost of air pollution, which is important for downstream design and evaluation of strategies and/or policies for cost-effectiveness.

Additionally, heterogeneity in associations have not been fully explained. Cross-country studies and meta-analyses have revealed variations in strength of associations between air pollutant levels and emergency department (ED) visits and hospital admissions across geographical regions, seasons and lag duration., ${ }^{2,14-17}$ These variations have been attributed to differences in demographics, use of air conditioning, time spent outdoors and chemical composition of fine PM with diameter $<2.5 \mu \mathrm{m}\left(\mathrm{PM}_{2.5}\right)$; all these factors may reflect differences in sources of air pollution. ${ }^{18,19}$ Young children and the elderly are also more vulnerable to the effects of air pollution. ${ }^{20-2}$

In Singapore, members of the public are informed about air quality by the National Environment Agency (NEA) through the 24-hour Pollutant Standards Index (PSI), a scale originally developed by the Environmental Protection Agency in the United States (US). ${ }^{23}$ PSI is used by several countries including the US and Brunei. Findings from case-crossover studies have demonstrated a link between higher PSI readings and increased acute health events and mortality. ${ }^{24-7}$

Despite findings on the adverse effects haze has on the health of Singaporeans, a comprehensive study of its impact on health services is lacking. Previously, our group has demonstrated associations between PSI and out-of-hospital cardiac arrest, acute ischaemic stroke, acute myocardial infarction and all-cause mortality. ${ }^{24-7}$ In 1997 , the haze crisis led to an increase of $30 \%$ in outpatient visits throughout the country, ${ }^{28}$ with a higher number of residents reporting mouth, throat and eye irritations. ${ }^{29}$ Although a study in Singapore included PSI as a predictor to forecast ED visits between 2005 and 2008, the focus was on a single hospital and on prediction rather than an attempt to quantify the risk air pollution poses to health. ${ }^{23}$ Identification of vulnerable subgroups would also facilitate better planning and management of health resources and services during episodes of haze.

Singapore is a highly urbanised tropical city-state who sees slight variations in weather patterns. ${ }^{23}$ Located near the Equator, her climate is hot and highly humid with abundant rainfall throughout the year. During this study, $80 \%$ of the health and medical needs of the population were met by 8 public acute hospitals, ${ }^{30,31}$ and they received about 1 million ED visits annually. ${ }^{32}$

In this study, we investigated the impact of air pollution exposure on ED visits to all public hospitals in Singapore and hospital admissions through ED. The analysis was stratified according to clinical and demographic characteristics to identify vulnerable subgroups. We also investigated the extent of delayed effects - up to 6 days - of air pollution before ED visit.

\section{Materials and Methods}

Anonymised administrative and basic clinical data of all ED visits to public hospitals between January 2010 and December 2015 were obtained from the Ministry of Health $(\mathrm{MOH})$, Singapore, and analysed. Data included age, gender, visit date and time, hospital, diagnosis code, patient acuity and patient movement after ED visit.

Primary outcome was defined as the daily total number of ED visits to public hospitals. Transfers to another ED within 12 hours from the prior visit were considered a single visit. For these cases, date and time were taken from the first ED visit and patient acuity, diagnosis and patient movement were taken from the last ED visit. Secondary outcome was defined as the daily number of hospital admissions through ED. Both outcomes were also examined according to subgroups defined a priori based on diagnoses, patient acuity, time of day, age group and gender. Unfortunately, information on ethnicity was not available.

Diagnoses were grouped into 6 categories according to the International Classification of Diseases (ICD) codes: ${ }^{33}$ 1) cardiovascular diseases (ICD-9: 390-429, 439-59, 785; ICD-10: I00-I59, I70-I99, R00-R01, R03); 2) cerebrovascular diseases (ICD-9: 320-89, 430-8, 781; ICD-10: G00-G99, I60-9, R25-9); 3) gastrointestinal diseases (ICD-9: 520-79; ICD-10: K00-K95); 4) neuropsychiatric diseases (ICD-9: 290-319; ICD-10: F00-F99); 5) respiratory diseases (ICD-9: 460-519, 786; ICD-10: J00-J99, R04-09); and 6) other diseases (all other ICD-9 and ICD-10 codes). 
Based on definitions provided by $\mathrm{MOH}$, patient acuity was classified as P1 (patients of resuscitation, cardiovascular collapse or imminent danger of collapse, required to be attended to without a moment's delay), P2 (patients of non-resuscitation, major emergency or ill and non-ambulant or having severe symptoms and trolley-based), P3 (patients of minor emergency or ambulant with mild or moderate symptoms) or P4 (non-emergency cases that do not require immediate medical attention).$^{34}$ Time of day was demarcated into day time (0700-1859 hours) and night time (1900-0659 hours) as a proxy for physical activity. Additionally, the daily number of patients who were subsequently admitted from ED of public hospitals were reviewed and classified according to the subgroups described above.

The primary exposure of interest was the 24-hour PSI. PSI readings were derived from measurements of 6 air pollutants: carbon monoxide, $\mathrm{NO}_{2}, \mathrm{O}_{3}, \mathrm{PM}_{2.5}, \mathrm{PM}$ diameter $<10 \mu \mathrm{m}\left(\mathrm{PM}_{10}\right)$ and $\mathrm{SO}_{2}$. Each pollutant was rated on a sub-index and translated into a sub-scale that ranged from $0-500$. PSI reading was derived by taking the maximum score from the 6 sub-indices. ${ }^{35}$ Measurements of air pollutants were collected by 22 telemetric air quality monitoring stations located in 5 regions across Singapore.

For our study, historical 24-hour PSI data were retrieved from the haze microsite maintained by NEA (www.haze.gov.sg). Data on daily rainfall, temperature and wind speed-measured at $>60$ weather stations across Singapore-were retrieved from the weather microsite of Meteorological Service Singapore (www. weather.gov.sg). For the purpose of statistical analysis, we derived the mean values of daily mean PSI, total rainfall, temperature and wind speed across all regions of Singapore.

Statistical analyses were performed in $\mathrm{R}$ version 3.5. $0^{36}$ using $\mathrm{R}$ package gnm. ${ }^{37}$ Conditional Poisson regression (gnm function and quasi-Poisson family) was used to model the effect of PSI on each clinical outcome according to year, month and week day, and to control for potential confounders such as daily rainfall, mean daily temperature and mean daily wind speed. Residual autocorrelation was checked by obtaining partial autocorrelation function (pacf) over the 6 days prior to the outcome (lags 1-6), and significant residuals were included as predictors. This modelling approach took into account seasonality, over-dispersion and autocorrelation..$^{38}$

To account for multiple tests, Bonferroni correction was applied to the entire cohort and 5 subgroups (diagnoses, patient acuity, time of day, age group and gender) since the categories in each subgroup were correlated. Further correction for multiple outcomes was not performed since they were correlated and it would be too conservative, potentially resulting in an error rate below the prescribed alpha value. ${ }^{39} \mathrm{~A}$ value of $P<0.008$ $(0.05 / 6)$ was considered statistically significant. Results were shown as estimated risk ratio (RR) and $99.2 \%$ confidence interval (CI) for every 30 -unit increment in PSI. This increment was chosen to facilitate comparison with findings from previous studies of PSI and other outcomes. ${ }^{24-7}$ To explore possible non-linear effects, PSI readings were categorised into good $(0-50)$, moderate $(51-100)$ and unhealthy $(>100)$ ranges, similar to the categories in use by NEA. ${ }^{35}$

Besides the study of same-day exposure, the possibility of delayed effects were examined through an analysis of lag effects of PSI for up to 6 days before the outcomes (lags 1-6). Unconstrained distributed lag model (DLM) was used to model all lag effects to account for confounding between lags. ${ }^{38}$ The cumulative effect of increased PSI over 7 days - which ends on the day of the outcome (day 6 to day 0 ) - was derived from DLM as sum of the coefficients. ${ }^{38}$ Results were shown as estimated RR and 95\% CI for every 30-unit increment in PSI.

Since it is plausible air pollution can increase temperature, there is a likelihood that temperature may be a mediating factor instead of a confounder. To account for this, all analyses were repeated without adjustment for temperature. As effect estimates tend to be slightly higher for less-adjusted models, it was likely temperature was a partial mediator. Consequently, results from both models were presented as graphs but only results from the less-adjusted model were reported.

\section{Results}

Between 2010 and 2015, a total of 5,791,945 ED visits resulted in 1,552,187 hospital admissions to public hospitals (Table 1). The environmental data was reported in an earlier study. ${ }^{26} \mathrm{ED}$ visits increased from 2010 to 2013 but remained relatively stable thereafter (Fig. 1). No significant increase in ED visits was seen with every 30-unit increase in PSI (RR, 1.002; 99.2\% CI, 0.995-1.008; $P=0.509$ ) in our study (Fig. 2), or with moderate (RR, $0.993 ; 99.2 \% \mathrm{CI}, 0.984-1.003 ; P=$ 0.084 ) or unhealthy (RR, $1.002 ; 99.2 \% \mathrm{CI}, 0.977-1.028$; $P=0.820$ ) PSI readings (Fig. 3).

Among the subgroups, a significant increase in ED visits was seen only in those with respiratory diseases with every 30-unit increase in PSI (RR, 1.023; 99.2\% CI, 1.011-1.036; $P=1.24 \times 10^{-6}$ ) (Fig. 2) and after the PSI dipped into the unhealthy range (RR, $1.082 ; 99.2 \% \mathrm{CI}$, 1.027-1.141; $\left.P=6.85 \times 10^{-5}\right)$ (Fig. 3). Except for time 
Table 1. Demographic and Clinical Characteristics of ED Visits $(\mathrm{n}=5,791,945)$ and Hospital Admissions $(\mathrm{n}=1,552,187)$

\begin{tabular}{|c|c|c|}
\hline Variable & ED Visits (\%) & Hospital Admissions (\%) \\
\hline \multicolumn{3}{|l|}{ Age (years) } \\
\hline$<21$ & $1,704,655(29.4)$ & $222,658(14.3)$ \\
\hline $21-64$ & $3,117,382(53.8)$ & $720,936(46.4)$ \\
\hline$\geq 65$ & $969,908(16.7)$ & $608,593(39.2)$ \\
\hline Male gender & $3,437,964(59.4)$ & $849,843(54.8)$ \\
\hline \multicolumn{3}{|l|}{ Patient acuity } \\
\hline P1 & $337,150(6.5)$ & $309,920(20.0)$ \\
\hline $\mathrm{P} 2$ & $2,239,881(38.7)$ & $965,656(62.2)$ \\
\hline P3, P4 and unknown & $3,174,914(54.8)$ & $276,611(17.8)$ \\
\hline \multicolumn{3}{|l|}{ Time of day (hours) } \\
\hline Day time $(0700-1859)$ & $2,024,045(34.9)$ & $516,158(33.3)$ \\
\hline Night time $(1900-0659)$ & $3,720,577(64.2)$ & $1,020,196(65.7)$ \\
\hline Unknown & $47,323(0.8)$ & $15,833(1.0)$ \\
\hline \multicolumn{3}{|l|}{ Diagnosis } \\
\hline Cardiovascular diseases & $239,055(4.1)$ & $145,839(9.4)$ \\
\hline Cerebrovascular diseases & $367,149(6.3)$ & $112,420(7.2)$ \\
\hline Gastrointestinal diseases & $497,632(8.6)$ & $150,089(9.7)$ \\
\hline Neuropsychiatric diseases & $135,661(2.3)$ & $52,996(3.4)$ \\
\hline Respiratory diseases & $1,195,297(20.6)$ & $262,308(16.9)$ \\
\hline Other diseases & $3,357,151(58.0)$ & $828,535(53.4)$ \\
\hline
\end{tabular}

ED: Emergency department

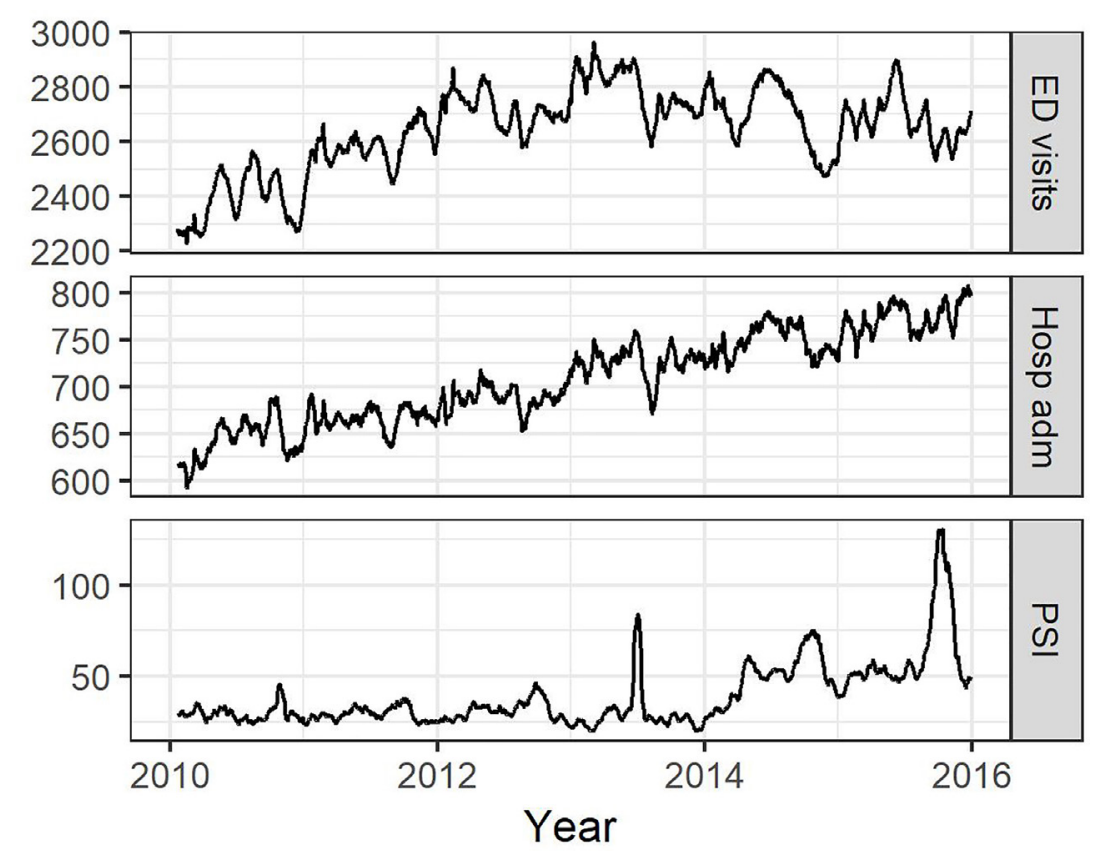

Fig. 1. Three-week moving averages of daily PSI, ED visits and hospital admissions. To smooth the data, arithmetic mean values of daily mean PSI, daily ED visits and daily hospital admissions over the past 21 days were calculated. ED: Emergency department; Hosp adm: Hospital admissions; PSI: Pollutant Standards Index 


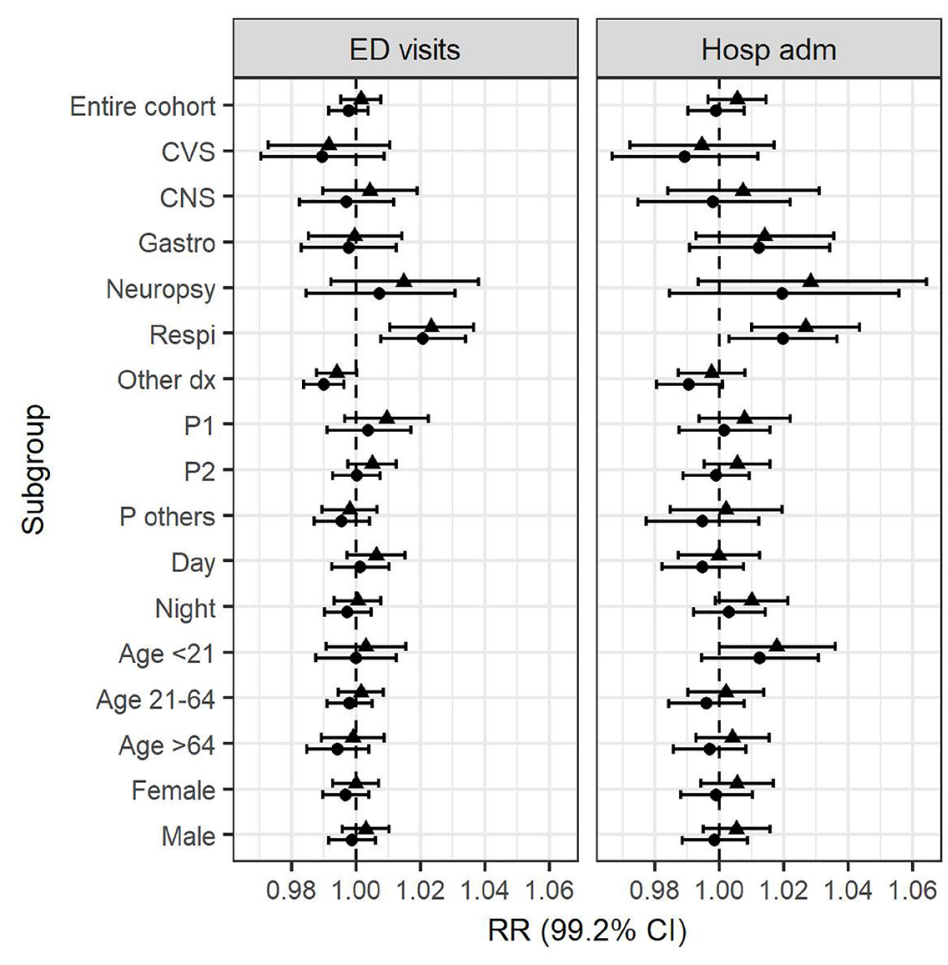

\section{Confounders}

- RTW

$\triangle \mathrm{RW}$

Fig. 2. Association between PSI, ED visits and hospital admissions. Relative risk (RR) is for every 30 -unit increase in PSI. For each outcome, results are shown for analyses after adjusting for all environmental confounders (circles) and excluding temperature (triangles). CI: Confidence interval; CNS: Central nervous system; CVS: Cardiovascular; dx: Diagnoses; ED: Emergency department; Gastro: Gastrointestinal; Hosp adm: Hospital admissions; Neuropsy: Neuropsychiatric; PSI: Pollutant Standards Index; Respi: Respiratory; RTW: Rain, temperature and wind; RW: Rain and wind

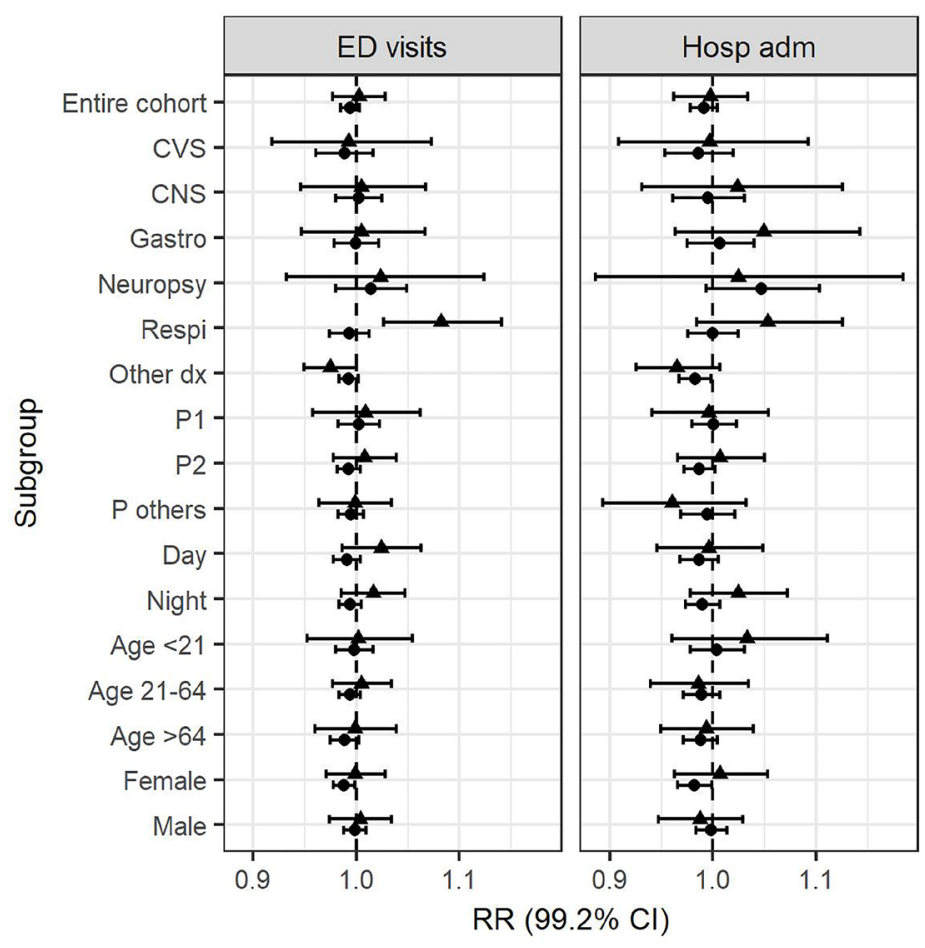

PSI category

- Moderate

- Unhealthy

Fig. 3. Association between categorical PSI, ED visits and hospital admissions. Only results that have been adjusted for rain and wind are shown. Relative risks (RR) are for PSI readings in the moderate (51-100) and unhealthy $(>100)$ ranges compared to good $(0-50)$ range. CI: Confidence interval; CNS: Central nervous system; CVS: Cardiovascular; dx: Diagnoses; ED: Emergency department; Gastro: Gastrointestinal; Hosp adm: Hospital admissions; Neuropsy: Neuropsychiatric; PSI: Pollutant Standards Index; Respi: Respiratory 
of day and age group, no differential effect was found after ED visits for respiratory conditions were classified according to the characteristics of each subgroup. More respiratory ED visits were seen during the day (RR, $1.039 ; 99.2 \%$ CI, 1.023-1.056; $\left.P=5.12 \times 10^{-11}\right)$, in patients aged $21-64$ years old (RR, 1.042; 99.2\% CI, $\left.1.042-1.057 ; P=3.33 \times 10^{-14}\right)$ and $>64$ years old $(\mathrm{RR}$, $1.022 ; 99.2 \%$ CI, 1.002-1.044; $P=0.004$ ) (Fig. 4).

No significant effect of PSI was found for total number of ED visits from lags 1-6. While ED visits for respiratory conditions were significantly higher on the same day (RR, 1.023; 95\% CI, 1.008-1.038), they were lower at lag 6 (RR, 0.983; 95\% CI, 0.969-0.997). Overall, ED visits for other diagnoses were significantly lower when PSI readings were higher on the same day to 6 days prior (cumulative RR, $0.985 ; 95 \% \mathrm{CI}$, 0.979-0.992) (Fig. 5).

Throughout our study, hospital admissions rose steadily (Fig. 1). Overall, no significant rise in the total number of hospital admissions was seen with every 30-unit increase in PSI (RR, 1.005; 99.2\% CI, 0.996-1.014; $P$ $=0.112)($ Fig. 2$)$ or with moderate (RR, 0.991; 99.2\% CI, 0.978-1.004; $P=0.073$ ) or unhealthy (RR, 0.997; 99.2\% CI, 0.962-1.034, $\mathrm{P}=0.832$ ) PSI readings (Fig. 3).
Among the subgroups, only admissions for respiratory conditions rose significantly with higher PSI readings (RR, 1.027; 99.2\% CI, 1.010-1.043; $P=2.02 \times 10^{-5}$ ) (Fig. 2). For respiratory illnesses that required hospital admissions, the effect sizes were very similar across subgroups (Fig. 4).

A slight drop in the total number of hospital admissions was seen at lag 5 (RR, 0.986; 95\% CI, 0.975-0.997). For respiratory conditions, same-day exposure led to an increase in admissions (RR, $1.025 ; 95 \% \mathrm{CI}$, 1.007-1.043); the cumulative effect-including 6 days prior-was also positive (cumulative RR, 1.020; 95\% CI, 1.002-1.038). For other diagnoses, a negative, cumulative effect of PSI on hospital admissions was found (cumulative RR, 0.984; 95\% CI, 0.973-0.995) in our study (Fig. 5).

\section{Discussion}

In this systematic study of the association between PSI readings and ED visits and subsequent hospital admissions throughout Singapore, we did not find a significant increase in total number of ED visits or hospital admissions. Instead, a significant increase in ED visits and hospital admissions attributed to respiratory

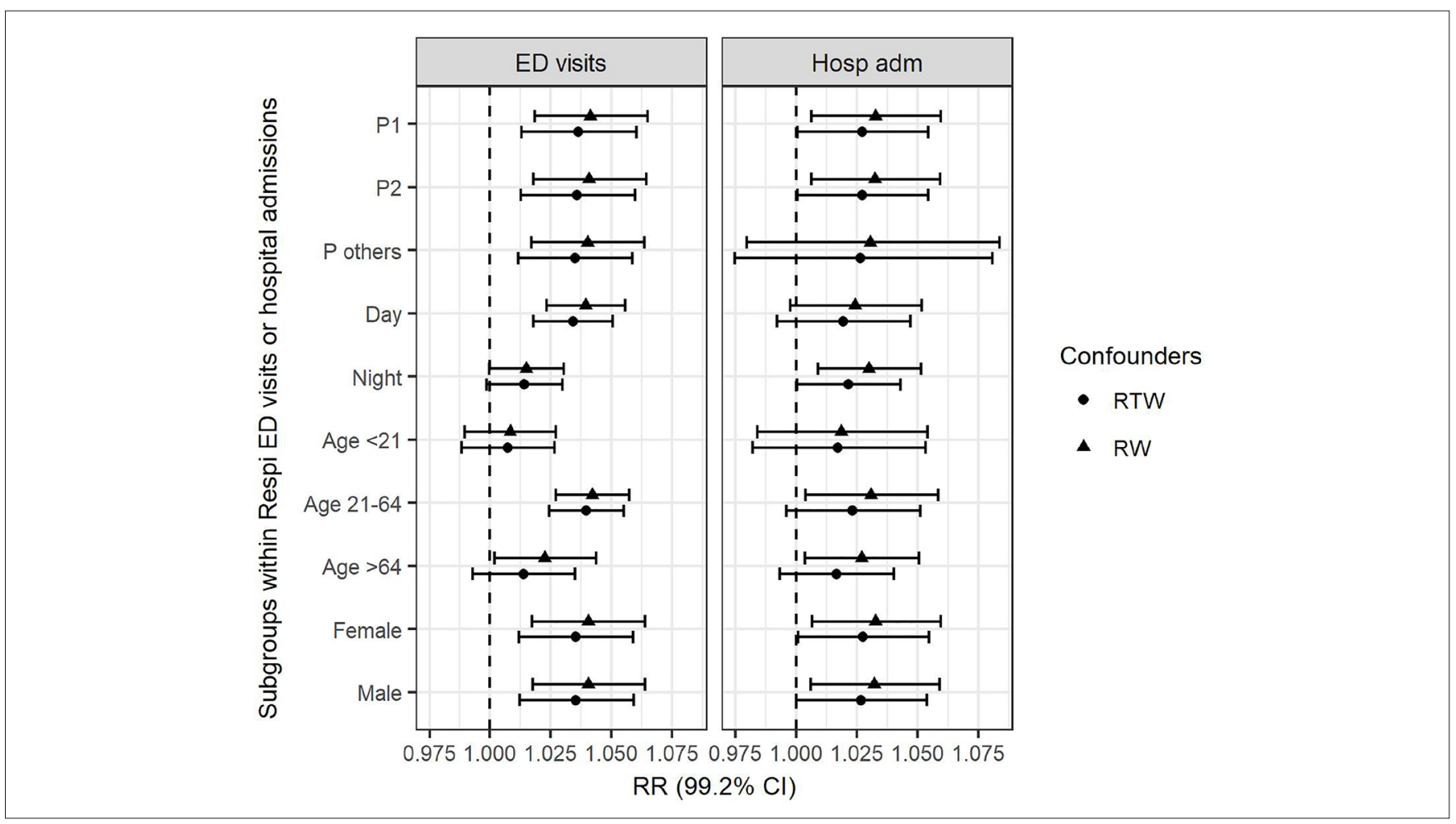

Fig. 4. Association between PSI, respiratory ED visits and hospital admissions by subgroups. Relative risk (RR) is for every 30 -unit increase in PSI. For each outcome, results are shown for analyses after adjusting for all environmental confounders (circles) and excluding temperature (triangles). CI: Confidence interval; ED: Emergency department; Hosp adm: Hospital admissions; PSI: Pollutant Standards Index; Respi: Respiratory; RTW: Rain, temperature and wind; RW: Rain and wind 


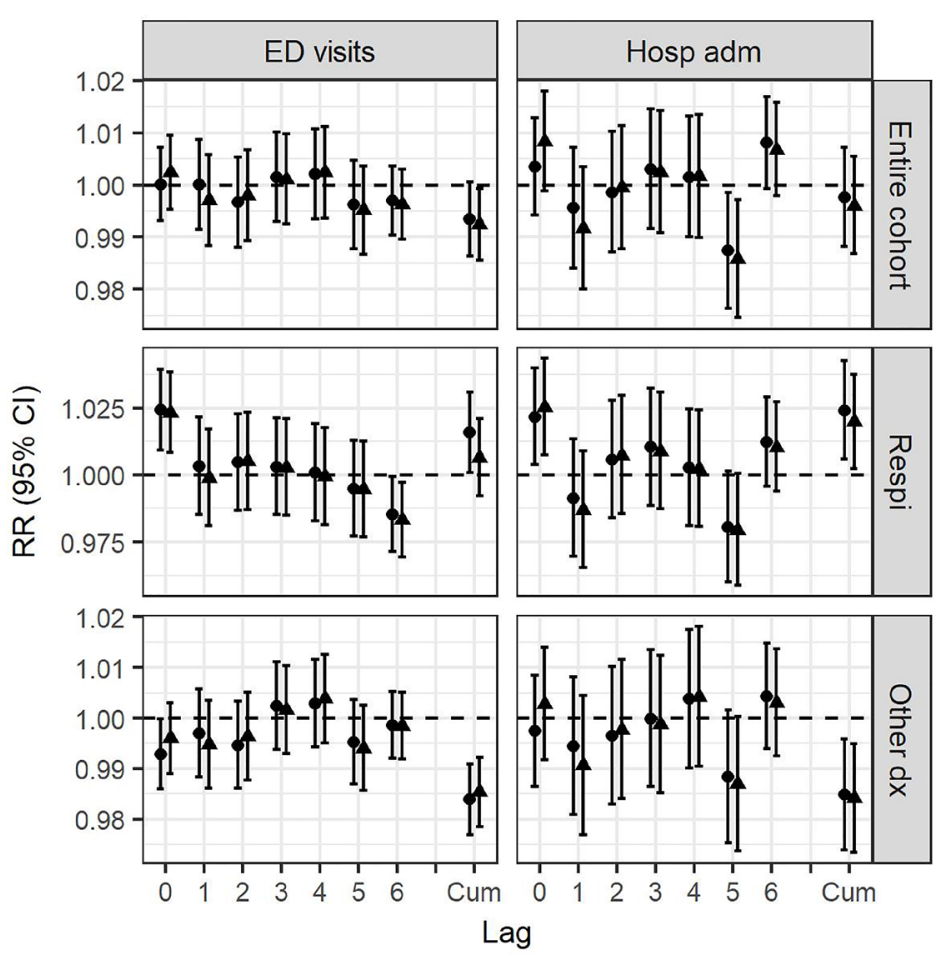

Confounders

- RTW

$\triangle \mathrm{RW}$

Fig. 5. Delayed effects of PSI on ED visits and hospital admissions. Relative risks (RR) are for every 30-unit increase in PSI and were derived from unconstrained distributed lag models that modelled exposure for all lags together. Cumulative effect of PSI exposure on day of outcome and past 6 days is indicated as "cum". Results from the fully adjusted model (circles) and the model that excluded temperature (triangles) are shown. Only the total number and selected subgroups are presented. CI: Confidence interval; dx: Diagnosis; ED: Emergency department; Hosp adm: Hospital admission; PSI: Pollutant Standards Index; Respi: Respiratory; RTW: Rain, temperature and wind; RW: Rain and wind

conditions with increased PSI readings was found. This finding concurred with results from other reports that found similar associations for asthma, chronic obstructive pulmonary disease and pneumonia. ${ }^{3-5,17,40}$ Every 30 -unit increase in PSI was associated with a 2\% increase in ED visits for respiratory conditions. Since public hospitals attend to about 550 such visits on a normal day, this finding translates into 11 more cases a day when the PSI is elevated by 30 units. During a haze episode, the PSI level can rise from a daily mean of 33 to $>200$; this works out to 40-60 more ED visits for respiratory illnesses each day.

A surprising finding of this study was the higher number of ED visits by young adults for respiratory ailments than the elderly or young children, who were presumed to be more vulnerable to the effects of air pollutant exposure. , $^{3,1541,42}$ Additionally, more ED visits were seen in young adults during day time, suggesting that outdoor activity could be related to exacerbations of respiratory diseases that prompted visits to the ED. During a haze episode, fine PM in the air can penetrate deep into the airways leading to inflammation and airway responsiveness in sensitised individuals. ${ }^{43}$
In view of this finding, it is hypothesised that when the PSI reached unhealthy levels, the elderly and young children comply with the advisory issued by the health authorities to minimise all outdoor activity and physical exertion; young adults, on the other hand, who are sensitised - but not necessarily diagnosed with asthmaor have mild intermittent asthma, consider themselves "healthy persons" and therefore do not see the need to reduce their outdoor activity and physical exertion. ${ }^{35}$

It is also hypothesised that asthmatic adults do not take enough precautions to avoid outdoor activity. Studies have shown a mismatch between actual outcomes and perceptions of patients on asthma control. ${ }^{44}$ Consequently, their response-in terms of compliance with medications, follow-up and, in this case, avoidance of air pollution-may be suboptimal. Further research on ED visits for specific respiratory diseases would yield more insight on the matter.

Interestingly, we did not find an increase in cardiovascular-related ED visits or hospital admissions. Systematic reviews have found a positive — but modestassociation between $\mathrm{PM}_{2.5}$ and cardiovascular ED visits 
and hospital admissions; however, the results could be influenced by differences in outcome definitions. ${ }^{2,45}$ The effect sizes for congestive heart failure and myocardial infarction are higher than that for any cardiovascular disease, which is close to the null. ${ }^{2,45}$

In light of this, the results of this study corroborated earlier findings from other studies. An increase in specific, susceptible cardiovascular conditions might have been diluted by other non-susceptible conditions. A recent study also found that $\mathrm{PM}_{2.5}$ and $\mathrm{PM}_{10}$ were risk factors for non-accidental and cardiovascular mortality in Singapore, especially in the elderly. ${ }^{46}$

In our study, the finding of an overall null effect for cardiovascular-related or elderly ED visits could be attributed to the fact that the general population required medical attention for mostly minor and haze-related ailments; however, the elderly have higher mortality risk from greater prevalence of comorbidities. For example, $88 \%$ of patients seen at a respiratory clinic had non-severe asthma. ${ }^{47}$ Finally, it is also possible that PSI is not as sensitive as $\mathrm{PM}_{2.5}$ in terms of finding an association with cardiovascular conditions.

A strength of this study was the availability of outcome data from all public hospitals in Singapore. Since 80\% of tertiary health needs are met by the public health sector, the data represented the most complete findings on the burden and impact of air pollutant exposure on health services. ${ }^{32}$ Accurate measurements of air pollutant exposure from 22 air quality monitoring stations across the country were also available. Finally, all-cause and subgroup-specific outcomes were investigated in this study that allowed direct comparisons and identification of vulnerable subgroups.

A limitation of this study was lack of data on individual behaviour that might affect their level of air pollutant exposure-such as time spent indoors and use of air conditioning, air purifiers and/or face masks-even though Singapore is a small city-state and her air quality is almost uniform across the island. Nevertheless, the focus of the study was to determine the impact of air pollutant exposure from the perspective of resource planning. Second, the diagnostic categories for subgroup analyses were too broad, but this provided an examination of more characteristics across a wider spectrum that facilitated a more systematic investigation and identification of directed hypotheses for future study. Third, even though data on pre-existing medical conditions was lacking, existing data still generated useful insights that can help in formulation of health policies and planning of health resources. Fourth, there was no data on each pollutant, and the impact of each on human health can be varied. The PSI reflects the most abundant pollutant found in the atmosphere during a haze episode which is $\mathrm{PM}_{10}$, and much of $\mathrm{PM}_{10}$ comprises $\mathrm{PM}_{2.5}{ }^{35,48}$ The concentration of $\mathrm{PM}_{10}$ is also consistently low with little variations in the absence of haze, but increased significantly during episodes of transboundary haze; ${ }^{49}$ consequently, the results of this study largely reflected the effect of PM.

\section{Conclusion}

Air pollution exposure did not increase overall utilisation of health services in Singapore. However, ED visits to treat respiratory conditions increased during haze episodes, and hospitals must be prepared to meet the surge in demand for medical services and treatment when the country is hit by another episode of haze. A group of patients that require further investigation are young adults who visit ED for respiratory conditions, such as the behaviours and motivations that prompt them to do so which contribute to the surge in demand for health services during periods of heightened air pollution.

\section{Acknowledgements}

The authors would like to thank the following Heads of Department for their help with data and support from their respective departments: Dr Lim Hoon Chin (Department of Accident and Emergency, Changi General Hospital), Dr Lee Khai Pin (Department of Emergency Medicine, KK Women's and Children's Hospital), Dr Sanjay Anikumar Patel (Department of Acute and Emergency Care, Khoo Teck Puat Hospital), Dr Quek Lit Sin (Emergency Medicine Department, Ng Teng Fong General Hospital), A/Prof Malcolm Mahadevan (Emergency Medicine Department, National University Hospital), Dr Kenneth Tan Boon Kiat (Department of Emergency Medicine, Singapore General Hospital) and Adjunct Assistant Professor Ang Hou (Emergency Department, Tan Tock Seng Hospital).

\section{REFERENCES}

1. Atkinson RW, Mills IC, Walton HA, Anderson HR. Fine particle components and health-a systematic review and meta-analysis of epidemiological time series studies of daily mortality and hospital admissions. J Expo Sci Environ Epidemiol 2015;25:208-14.

2. Atkinson RW, Kang S, Anderson HR, Mills IC, Walton HA. Epidemiological time series studies of $\mathrm{PM}_{2.5}$ and daily mortality and hospital admissions: a systematic review and meta-analysis. Thorax 2014;69:660-5.

3. Luong LMT, Sly PD, Thai PK, Phung D. Impact of ambient air pollution and wheeze-associated disorders in children in Southeast Asia: a systematic review and meta-analysis. Rev Environ Health 2019;34:125-39.

4. Wang K, Hao Y, Au W, Christiani DC, Xia ZL. A systematic review and meta-analysis on short-term particulate matter exposure and chronic obstructive pulmonary disease hospitalizations in China. J Occup Environ Med 2019;61:e112-24. 
5. DeVries R, Kriebel D, Sama S. Outdoor air pollution and COPDrelated emergency department visits, hospital admissions, and mortality: a meta-analysis. COPD 2017;14:113-21.

6. World Health Organization. Ambient air pollution - a major threat to health and climate. Available at: https://www.who.int/airpollution/ ambient/en/. Accessed on 14 March 2019.

7. Hon PML. Singapore. In: Jessup T, Glover D, editors. Indonesia's Fires and Haze: The Cost of Catastrophe. Singapore: ISEAS/ IDRC; 2006. p. 51-85.

8. Sastry N. Forest fires, air pollution, and mortality in Southeast Asia. Demography 2002;39:1-23.

9. Reddington CL, Yoshioka M, Balasubramanian R, Ridley D, Toh YY, Arnold SR, et al. Contribution of vegetation and peat fires to particulate air pollution in Southeast Asia. Environ Res Lett 2014;9:1-12.

10. Ho RC, Zhang MW, Ho CS, Pan F, Lu Y, Sharma VK. Impact of 2013 South Asian haze crisis: study of physical and psychological symptoms and perceived dangerousness of pollution level. BMC Psychiatry 2014;14:1-8.

11. Budisulistiorini SH, Riva M, Williams M, Miyakawa T, Chen $\mathrm{J}$, Itoh $\mathrm{M}$, et al. Dominant contribution of oxygenated organic aerosol to haze particles from real-time observation in Singapore during an Indonesian wildfire event in 2015. Atmos Chem Phys 2018;18:16481-98.

12. Xu J, Tai X, Betha R, He J, Balasubramanian R. Comparison of physical and chemical properties of ambient aerosols during the 2009 haze and non-haze periods in Southeast Asia. Environ Geochem Health 2015;37:831-41.

13. Zhou J, Chen A, Cao Q, Yang B, Chang VWC, Nazaroff WW. Particle exposure during the 2013 haze in Singapore: importance of the built environment. Build Environ 2015;93:14-23.

14. Li M, Wu Y, Tian YH, Cao GY, Yao SS, Ai P, et al. A meta-analysis on the relations between short-term exposure to $\mathrm{PM}_{2.5}$ and both mortality and related emergency visits in China. Zhonghua Liu Xing Bing Xue Za Zhi 2018;39:1394-401.

15. Lim H, Kwon HJ, Lim JA, Choi JH, Ha M, Hwang SS, et al. Short-term effect of fine particulate matter on children's hospital admissions and emergency department visits for asthma: a systematic review and meta-analysis. J Prev Med Public Health 2016;49:205-19

16. Wong CM, Atkinson RW, Anderson HR, Hedley AJ, Ma S, Chau PYK, et al. A tale of two cities: effects of air pollution on hospital admissions in Hong Kong and London compared. Environ Health Perspect 2002 Jan;110:67-77.

17. Moore E, Chatzidiakou L, Kuku MO, Jones RL, Smeeth L, Beevers $\mathrm{S}$, et al. Global associations between air pollutants and chronic obstructive pulmonary disease hospitalizations. A systematic review. Ann Am Thorac Soc 2016;13:1814-27.

18. Medina-Ramón M, Zanobetti A, Schwartz J. The effect of ozone and $\mathrm{PM}_{10}$ on hospital admissions for pneumonia and chronic obstructive pulmonary disease: a national multicity study. Am J Epidemiol 2006;163:579-88.

19. Bell ML, Ebisu K, Peng RD, Samet JM, Dominici F. Hospital admissions and chemical composition of fine particle air pollution. Am J Respir Crit Care Med 2009;179:1115-20.

20. Johnson JE, Bael DL, Sample JM, Lindgren PG, Kvale DL. Estimating the public health impact of air pollution for informing policy in the twin cities: a Minnesota tracking collaboration. J Public Health Manag Pract 2017;23:S45-52.

21. Lin CM, Kuo HW. Sex-age differences in association with particulate matter and emergency admissions for cardiovascular diseases: a hospital-based study in Taiwan. Public Health 2013;127:828-33.
22. Zhang Y, Wang S, Fan X, Ye X. Temperature modulation of the health effects of particulate matter in Beijing, China. Environ Sci Pollut Res Int 2018;25:10857-66.

23. Sun Y, Heng BH, Seow YT, Seow E. Forecasting daily attendances at an emergency department to aid resource planning. BMC Emerg Med 2009;9:1.

24. Ho AFW, Zheng H, Cheong KH, En WL, Pek PP, Zhao X, et al. The relationship between air pollution and all-cause mortality in Singapore. Atmosphere (Basel) 2020;11:9.

25. Ho AFW, Zheng H, Earnest A, Cheong KH, Pek PP, Seok JY, et al. Time-stratified case crossover study of the association of outdoor ambient air pollution with the risk of acute myocardial infarction in the context of seasonal exposure to the Southeast Asian haze problem. J Am Heart Assoc 2019;8:e011272.

26. Ho AFW, Zheng H, De Silva DA, Wah W, Earnest A, Pang YH, et al. The relationship between ambient air pollution and acute ischemic stroke: a time-stratified case-crossover study in a citystate with seasonal exposure to the Southeast Asian haze problem. Ann Emerg Med 2018;72:591-601.

27. Ho AFW, Wah W, Earnest A, Ng YY, Xie Z, Shahidah N, et al. Health impacts of the Southeast Asian haze problem-a timestratified case crossover study of the relationship between ambient air pollution and sudden cardiac deaths in Singapore. Int J Cardiol 2018;271:352-8.

28. Emmanuel SC. Impact to lung health of haze from forest fires: the Singapore experience. Respirology 2000;5:175-82.

29. Ramakreshnan L, Aghamohammadi N, Fong CS, Bulgiba A, Zaki RA, Wong LP, et al. Haze and health impacts in ASEAN countries: a systematic review. Environ Sci Pollut Res Int 2018;25:2096-111.

30. Yeo SQ, Harris M, Majeed FA. Integrated care for diabetes-a Singapore approach. Int J Integr Care 2012;12:e8.

31. Ministry of Health, Singapore. Health facilities. Available at: https:// www.moh.gov.sg/content/moh web/home/statistics/Health Facts Singapore/Health_Facilities.html. Accessed on 14 March 2019.

32. Ministry of Health, Singapore. Admissions and outpatient attendances. Available at: https://www.moh.gov.sg/content/moh web/home/ statistics/Health Facts Singapore/Admissions and Outpatient Attendances.html. Accessed on 14 March 2019.

33. ICD9Data.com. 2015 ICD-9-CM diagnosis codes. Available at: http://www.icd9data.com/2015/Volume1/default.htm. Accessed on 7 June 2018.

34. Singapore General Hospital. Emergency care. Available at: https:// www.sgh.com.sg/patient-care/visiting-specialist/emergency-caresingapore-general-hospital. Accessed on 11 March 2020.

35. National Environment Agency, Singapore. Air pollution: FAQs. Available at: https://www.nea.gov.sg/our-services/pollution-control/ air-pollution/faqs. Accessed on 14 March 2019.

36. R Core Team. R: a language and environment for statistical computing. Vienna, Austria: R Foundation for Statistical Computing; 2018.

37. Turner H, Firth D. Generalized nonlinear models in R: an overview of the gnm package for gnm version 1.1-1,2020. Available at: https:// cran.r-project.org/web/packages/gnm/vignettes/gnmOverview.pdf. Accessed on 11 March 2020.

38. Bhaskaran K, Gasparrini A, Hajat S, Smeeth L, Armstrong B. Time series regression studies in environmental epidemiology. Int J Epidemiol 2013;42:1187-95.

39. Streiner DL, Norman GR. Correction for multiple testing: is there a resolution? Chest 2011;140:16-8.

40. Nhung NTT, Amini H, Schindler C, Joss MK, Dien TM, ProbstHensch N, et al. Short-term association between ambient air pollution and pneumonia in children: a systematic review and 
meta-analysis of time-series and case-crossover studies. Environ Pollut 2017;230:1000-8.

41. Fan J, Li S, Fan C, Bai Z, Yang K. The impact of $\mathrm{PM}_{2.5}$ on asthma emergency department visits: a systematic review and metaanalysis. Environ Sci Pollut Res Int 2016;23:843-50.

42. Zheng XY, Ding H, Jiang LN, Chen SW, Zheng JP, Qiu M, et al. Association between air pollutants and asthma emergency room visits and hospital admissions in time series studies: a systematic review and meta-analysis. PLoS One 2015;10:e138146.

43. Gavett SH, Koren HS. The role of particulate matter in exacerbation of atopic asthma. Int Arch Allergy Immunol 2001;124:109-12.

44. Koh MS, Yii AC, Ong YY. Asthma in Singapore: past, present and future. Ann Acad Med Singapore 2017;46:81-3.

45. Luben TJ, Nichols JL, Dutton SJ, Kirrane E, Owens EO, DatkoWilliams L, et al. A systematic review of cardiovascular emergency department visits, hospital admissions and mortality associated with ambient black carbon. Environ Int 2017;107:154-62.

46. Yap J, Ng Y, Yeo KK, Sahlén A, Lam CSP, Lee V, et al. Particulate air pollution on cardiovascular mortality in the tropics: impact on the elderly. Environ Health 2019;18:34.

47. Tay TR, Wong HS, Ihsan R, Toh HP, Choo X, Tee AKH. Comparison of the proportion and healthcare utilisation of adult patients with uncontrolled severe asthma versus non-severe asthma seen in a Southeast Asian hospital-based respiratory specialist clinic. Ann Acad Med Singapore 2017;46:217-28.

48. Khoo KL. The haze and health: a blog about the fog. Ann Acad Med Singapore 2006;35:909-10.

49. Urbančok D, Payne AJR, Webster RD. Regional transport, source apportionment and health impact of $\mathrm{PM}_{10}$ bound polycyclic aromatic hydrocarbons in Singapore's atmosphere. Environ Pollut 2017;229:984-93. 